\title{
BMJ Open Relationship between uric acid and technique failure in patients on continuous ambulatory peritoneal dialysis: a long-term observational cohort study
}

\author{
Yao-Peng Hsieh, ${ }^{1,2,3,4}$ Chia-Chu Chang, ${ }^{2,4}$ Chew-Teng Kor, ${ }^{2}$ Yu Yang, ${ }^{2,4}$ \\ Yao-Ko Wen, ${ }^{2}$ Ping-Fang Chiu, ${ }^{2,4}$ Chi-Chen Lin $^{5}$
}

To cite: Hsieh Y-P Chang C-C, Kor C-T, et al. Relationship between uric acid and technique failure in patients on continuous ambulatory peritoneal dialysis: a long-term observational cohort study. BMJ Open 2017;7:e010816. doi:10.1136/bmjopen-2015010816

- Prepublication history for this paper is available online. To view these files please visit the journal online (http://dx.doi.org/10.1136/ bmjopen-2015-010816).

Y-PH and C-CL contributed equally.

Received 9 December 2015 Revised 27 April 2016 Accepted 2 June 2016

CrossMark

For numbered affiliations see end of article.

Correspondence to Dr Yao-Peng Hsieh; 102407@cch.org.tw

\section{ABSTRACT}

Objectives: Uric acid (UA) is the product of purine or nucleotide metabolism via the pathway of xanthine oxidase or xanthine dehydrogenase. Although epidemiological studies assessing the role of UA in cardiovascular disease or mortality have produced inconsistent results, the correlation between UA and technique failure in patients on continuous ambulatory peritoneal dialysis (CAPD) remains to be assessed.

Design: A retrospective cohort study.

Setting: Patients starting CAPD between 2001 and 2009 in a single centre in Taiwan.

Participants: A total of 371 patients on CAPD.

Primary outcome measures: All-cause and peritonitis-related technique failure.

Results: A cohort of 371 participants (43.9\% male) was enrolled in the study with a mean age of 55.7 \pm 15.9 years at the start of CAPD. During the study period, technique failure occurred in 41 (34.4\%) patients in the hyperuricaemia group compared with 49 $(19.4 \%)$ in the normouricaemia group $(p=0.003)$. In the multivariate Cox regression models, hyperuricaemia at baseline was significantly associated with both a higher risk of technique failure (HR 1.24; 95\% Cl 1.09 to $1.42, p=0.001$ ) and peritonitis-related technique failure (HR 1.29; 95\% Cl 1.07 to 1.57, $p=0.008$ ).

Conclusions: UA was shown to be associated with all-cause and peritonitis-related technique failure in our study. Patients on CAPD with hyperuricaemia should be closely monitored and strategies of increasing survival on CAPD should be taken.

\section{INTRODUCTION}

Since life expectancy has been increased with the development of modern medical care, the prevalence of chronic kidney disease (CKD) has also been growing to become a global health problem. Uric acid (UA) is the product of purine or nucleotide metabolism

\section{Strengths and limitations of this study}

- Measurement of uric acid is a simple, inexpensive and accessible biomarker in clinical practice.

- Uric acid may help identify patients at high risk of technique failure.

- There are still possibilities that some potential confounders were not assessed in our study, such as reactive oxygen species.

- Our study population was performed only in a single medical centre, limiting the generalisability of our novel findings.

- The underlying mechanisms linking hyperuricaemia to technique failure cannot be clearly answered from the current study.

via the pathway of xanthine oxidase or xanthine dehydrogenase, and most UA is excreted by glomerular filtration. ${ }^{1}$ Hyperuricaemia closely coexists with CKD due to impaired glomerular filtration rate, and the major route of UA excretion is the gastrointestinal tract in the environment of CKD. It has also been reported that some UA is excreted from the interaction with peroxynitrite. ${ }^{2}$

UA has been reported to be frequently linked with some established cardiovascular risk factors, such as diabetes, hypertension, dyslipidaemia and obesity. ${ }^{3}{ }^{4}$ However, epidemiological studies assessing the role of UA in cardiovascular disease (CVD) or mortality have produced inconsistent results. ${ }^{5}{ }^{6}$ Some findings suggest an independent risk for UA, whereas others indicate concomitant CVD risk factors. A J-shaped relationship between UA and all-cause mortality has been reported in patients on peritoneal dialysis (PD). ${ }^{7} \mathrm{~A}$ Chinese study of patients on PD concluded that hyperuricaemia is an independent risk factor for all-cause mortality. ${ }^{8}$ 
After the introduction of continuous ambulatory PD (CAPD) as a renal replacement in the late 1970s, the acceptance of CAPD as an effective modality for endstage renal disease (ESRD) has been increasing, especially recently, in comparison with haemodialysis (HD) ${ }^{9}$ This is in part due to the conflicting conclusions reported on the survival benefits between CAPD and HD. Even with the advances in technical development, patient education and better appreciation of risk factors, peritonitis and PD dropout still remain widespread. Furthermore, the risk of transferring to HD was the highest in the first few months of PD initiation, primarily because of peritonitis. ${ }^{10}$ To the best of our knowledge, the association of UA with technique failure in CAPD has never been reported. The aim of this study was therefore to determine the correlation between UA and technique failure in patients on CAPD.

\section{PATIENTS AND METHODS}

We conducted a retrospective study with the aim of elucidating the role of UA in the development of technique failure in a single medical centre in Taiwan. The study cohort was those patients who started CAPD as the renal replacement therapy between 2001 and 2009. A total of 371 participants were the study participants. The study outcomes were all-cause and peritonitis-related technique failure. The end of this study was on 31 December 2010.

Patients were given either conventional glucose-based solution or neutral Balance solution, which was recorded for further analysis. Treatment with icodextrin was also recorded. The first peritoneal equilibrium test (PET) and dialysis adequacy were done within 1 month of CAPD initiation and at a 3-month to 6-month interval thereafter. Using the hospital's database, we retrospectively retrieved demographic, clinical and outcome data. The collected comorbid conditions included diabetes mellitus (DM), hypertension, coronary artery disease, cerebrovascular disease and peripheral artery disease at baseline. Laboratory measurements encompassed haemoglobin, calcium, phosphate, glutamate pyruvate transaminase (GPT), ferritin, serum albumin, blood urea nitrogen (BUN) and creatinine level, all of which were checked at monthly or 3-monthly intervals. The collected medications included ACE inhibitor, angiotensin II receptor blocker (ARB), hypouricaemic agent (allopurinol), diuretics (furosemide), calcium channel blocker (CCB) and $\beta$-blocker. Technique failure was defined as drop out from PD and transfer to HD. The causes of technique failure included refractory peritonitis, ultrafiltration failure, dialysis inadequacy, exit-site and tunnel infection, mechanical problems, operation procedure or operational problems/ non-compliance or others. Non-compliance was defined as poor adherence to dialysis prescription, such as frequently missing dialysis exchanges.

Refractory peritonitis was the most common cause of technique failure in our cohort. The study outcomes in the study were all-cause technique failure and peritonitis-related technique failure. Hyperuricaemia was defined as a serum UA level of more than $8 \mathrm{mg} / \mathrm{dL}$, based on the colorimetric methods in our laboratory.

\section{Statistical analysis}

All data were expressed as the means \pm SD for continuous variables, or number $(n)$ and percentage $(\%)$ for categorical variables. Student's unpaired t-test, the Mann-Whitney test or $\chi^{2}$ test was used to compare data between two groups, as appropriate. Death, renal function recovery or a switch to renal transplantation was censored for technique failure analysis. We conducted the Kaplan-Meier survival analysis to compare technique failure between the hyperuricaemia and normouricaemia groups, and the log-rank test was used to determine significant differences. A multivariate Cox proportional hazards model was used to identify independent factors and to estimate the HR and the associated 95\% CIs. The analysed variables included gender, age, BMI, comorbid conditions, and the use of ACE inhibitor, ARB, $\beta$-blocker, CCB, hypouricaemic agents, diuretics, BUN, creatinine, haemoglobin, ferritin, serum albumin, Ca $\times$ P, GPT, residual renal function, icodextrin use, Balance dialysate use, assistance for dialysate exchanges, peritoneal $\mathrm{Kt} / \mathrm{V}$, weekly total $\mathrm{Kt} / \mathrm{V}$ urea, normalised protein nitrogen appearance (nPNA)), D/P (creatinine) at 4 hours, ultrafiltration, 24-hour urine output, and exit-site infection, tunnel infection, number of exchanges per day and peritonitis rate. To increase the robustness of our investigation, we performed three sensitivity analyses. First, the entire study cohort was divided into three tertiles by the UA level (model S1). Second, a cut-off value of $7 \mathrm{mg} / \mathrm{dL}$ for UA was chosen to group the study population for further analyses (model S2). Third, the analysis was repeated with UA as a continuous variable (model S3). All the probabilities were two tailed and the level of significance was set at a $\mathrm{p}$ value $<0.05$. All statistical analyses were carried out using IBM SPSS Statistics for Windows, Version 22.0 (IBM Corp., Armonk, NY).

\section{RESULTS}

\section{Patient characteristics and comparison of baseline covariates}

The baseline characteristics of the 371 participants are shown in table 1 . As can be seen in this table, $32.1 \%$ of the patients had hyperuricaemia at baseline, $43.9 \%$ were male, and the mean age was $55.72 \pm 15.99$ years (median \pm IQR, $56.29 \pm 22.23$ years) at the start of CAPD. The mean follow-up duration was $36.69 \pm 27.53$ months (median \pm IQR, 29.97 \pm 38.4 months). Compared with the normouricaemic group, the hyperuricemic one had more patients of male gender $(54.6 \%$ vs $38.8 \%$, $\mathrm{p}=0.006)$, younger age $(52.4 \pm 16.4$ vs $57.2 \pm 15.7, \mathrm{p}=0.006)$, more ultrafiltration $(0.44 \pm 0.79$ vs $0.3 \pm 0.79, \mathrm{p}=0.023)$, 
Table 1 Patients' characteristics by UA levels

\begin{tabular}{|c|c|c|c|c|}
\hline & Total patients & UA baseline $>8 \mathrm{mg} / \mathrm{dL}$ & UA baseline $\leq 8 \mathrm{mg} / \mathrm{dL}$ & p Value \\
\hline Number of patients & 371 & $119(32.10 \%)$ & $252(67.9 \%)$ & $<0.001^{*}$ \\
\hline Sex, men & 163 (43.94\%) & $65(54.62 \%)$ & $98(38.89 \%)$ & $0.006^{*}$ \\
\hline Age (years) & $55.72 \pm 15.99$ & $52.41 \pm 16.43$ & $57.28 \pm 15.57$ & $0.006^{*}$ \\
\hline Body mass index $\left(\mathrm{kg} / \mathrm{m}^{2}\right)$ & $22.77 \pm 3.82$ & $23.15 \pm 3.77$ & $22.6 \pm 3.84$ & 0.195 \\
\hline Follow-up time (months) & $29.97 \pm 38.32$ & $29.40 \pm 38.21$ & $31.17 \pm 38.35$ & 0.818 \\
\hline \multicolumn{5}{|l|}{ Assistant } \\
\hline Yes & $196(52.83 \%)$ & $68(57.14 \%)$ & $128(50.79 \%)$ & 0.302 \\
\hline \multicolumn{5}{|l|}{ Comorbid conditions } \\
\hline Diabetes mellitus & 117 (31.54\%) & 38 (31.93\%) & $79(31.35 \%)$ & 1.000 \\
\hline Hypertension & 305 (82.21\%) & 98 (82.35\%) & 207 (82.14\%) & 1.000 \\
\hline Coronary artery disease & $58(15.63 \%)$ & $18(15.13 \%)$ & $40(15.87 \%)$ & 0.975 \\
\hline Cerebrovascular disease & $32(8.63 \%)$ & $12(10.08 \%)$ & $20(7.94 \%)$ & 0.624 \\
\hline Peripheral artery disease & $8(2.16 \%)$ & $3(2.52 \%)$ & $5(1.98 \%)$ & 1.000 \\
\hline \multicolumn{5}{|l|}{ Medications } \\
\hline ACE inhibitor/ARB & $245(66.04 \%)$ & $82(68.91 \%)$ & $163(64.68 \%)$ & 0.494 \\
\hline Hypouricaemic agents (allopurinol) & $89(23.99 \%)$ & $33(27.73 \%)$ & $56(22.22 \%)$ & 0.303 \\
\hline Diuretics & $200(53.91 \%)$ & $70(58.82 \%)$ & $130(51.59 \%)$ & 0.233 \\
\hline Calcium channel blocker & 265 (71.43\%) & $89(74.79 \%)$ & $176(69.84 \%)$ & 0.389 \\
\hline$\beta$-blocker & $79(21.29 \%)$ & $29(24.37 \%)$ & $50(19.84 \%)$ & 0.391 \\
\hline \multicolumn{5}{|l|}{ PD-related parameters } \\
\hline Icodextrin use & $114(30.73 \%)$ & 37 (31.09\%) & $77(30.56 \%)$ & 1.000 \\
\hline Balance dialysate & $23(6.2 \%)$ & $4(3.36 \%)$ & $19(7.54 \%)$ & 0.184 \\
\hline Residual renal function $\left(\mathrm{mL} / \mathrm{min} / 1.73 \mathrm{~m}^{2}\right)$ & $2.53 \pm 2.68$ & $2.77 \pm 2.86$ & $2.45 \pm 2.59$ & 0.525 \\
\hline $\mathrm{D} / \mathrm{P}$ creatinine at 4 hours & $0.67 \pm 0.11$ & $0.67 \pm 0.11$ & $0.67 \pm 0.11$ & 0.619 \\
\hline Ultrafiltration (L/day) & $0.34 \pm 0.75$ & $0.44 \pm 0.79$ & $0.3 \pm 0.79$ & $0.023^{*}$ \\
\hline 24-hour urine volume (L) & $0.85 \pm 0.82$ & $0.8 \pm 0.7$ & $0.86 \pm 0.87$ & 0.402 \\
\hline $\mathrm{Kt} / \mathrm{V}$ for PD (weekly Kt/V) & $1.48 \pm 0.47$ & $1.48 \pm 0.39$ & $1.48 \pm 0.49$ & 0.946 \\
\hline Total weekly Kt/V & $2.08 \pm 0.56$ & $2.03 \pm 0.49$ & $2.12 \pm 0.56$ & 0.166 \\
\hline nPNA (g/kg/day) & $1.04 \pm 0.41$ & $1.08 \pm 0.37$ & $1.02 \pm 0.4$ & 0.067 \\
\hline Exit-site infection (per 100 patient-years) & $0.29 \pm 0.66$ & $0.36 \pm 0.66$ & $0.26 \pm 0.66$ & 0.162 \\
\hline Tunnel infection rate (per 100 patient-years) & $0.01 \pm 0.05$ & $0.01 \pm 0.06$ & $0.01 \pm 0.05$ & 0.495 \\
\hline Peritonitis rate (per year) & $0.18 \pm 0.35$ & $0.22 \pm 0.4$ & $0.16 \pm 0.32$ & 0.109 \\
\hline Number of exchanges per day & $4 \pm 0.22$ & $4 \pm 0.33$ & $4 \pm 0.19$ & 0.197 \\
\hline \multicolumn{5}{|l|}{ Laboratory data } \\
\hline Serum albumin (g/dL) & $3.52 \pm 0.74$ & $3.4 \pm 0.68$ & $3.58 \pm 0.8$ & 0.593 \\
\hline BUN (mg/dL) & $83.83 \pm 30.29$ & $95 \pm 29.86$ & $78.53 \pm 28.27$ & $<0.001^{*}$ \\
\hline Calcium (mg/dL) & $8.3 \pm 0.98$ & $8.25 \pm 0.94$ & $8.3 \pm 0.92$ & $0.047^{*}$ \\
\hline Phosphorus (mg/dL) & $5.4 \pm 1.89$ & $5.85 \pm 1.72$ & $5.24 \pm 1.71$ & $<0.001^{*}$ \\
\hline Calcium phosphate product $\left(\mathrm{mg}^{2} / \mathrm{dL}^{2}\right)$ & $43.89 \pm 14.45$ & $46.07 \pm 13.9$ & $42.63 \pm 13.97$ & $0.002^{*}$ \\
\hline Creatinine $(\mathrm{mg} / \mathrm{dL})$ & $9.5 \pm 3.87$ & $10.1 \pm 4.72$ & $9.22 \pm 3.45$ & $0.009^{*}$ \\
\hline Ferritin (ng/mL) & $266.8 \pm 341.85$ & $263.06 \pm 395.35$ & $270.81 \pm 320.77$ & 0.874 \\
\hline GPT (U/L) & $16 \pm 11.06$ & $16.33 \pm 10.95$ & $15.58 \pm 11.36$ & 0.675 \\
\hline Haemoglobin (g/dL) & $8.4 \pm 1.34$ & $8.21 \pm 1.44$ & $8.49 \pm 1.29$ & 0.07 \\
\hline $\mathrm{UA}(\mathrm{mg} / \mathrm{dL})$ & $7.33 \pm 1.92$ & $9.1 \pm 1.49$ & $6.72 \pm 1.25$ & $<0.001^{*}$ \\
\hline
\end{tabular}

Values are expressed as mean \pm SD or number (percentage).

*p Value $<0.05$

$\mathrm{ARB}$, angiotensin II receptor blocker; BUN, blood urea nitrogen; PD, peritoneal dialysis; UA, uric acid.

higher BUN $(95 \pm 29.8$ vs $78.5 \pm 28.7, \mathrm{p}<0.001)$, lower calcium $(8.2 \pm 0.9$ vs $8.3 \pm 0.9, \mathrm{p}=0.047)$, higher creatinine $(10.1 \pm 4.7$ vs $9.2 \pm 3.4, \mathrm{p}=0.009)$, higher phosphate $(5.8 \pm 1.7$ vs $5.2 \pm 1.7, \mathrm{p}<0.001)$ and higher calcium phosphate product $(46 \pm 13.9$ vs $42 \pm 13.9, \mathrm{p}=0.002)$. In addition, chronic glomerulonephritis $(n=114,30.7 \%)$ and DM $(n=102,27.5 \%)$ were the two most common causes of CKD for the whole cohort. The majority $(81.6 \%)$ of our patients were 'never smokers'.
Predialysis CKD $(98.5 \%)$ was the most common modality before PD.

\section{Causes of technique failure}

There were 90 patients having technique failure during the observation period. The reasons for technique failure are listed in table 2. Of the 90 patients switching to $\mathrm{HD}, 41(45.5 \%)$ participants were ascribed to peritonitis. The second most common cause of technique 
Table 2 Reasons for technique failure

\begin{tabular}{lllll}
\hline & Total & Uric acid >8 $\mathbf{~ m g / d L}$ & Uric acid $\mathbf{8} \mathbf{~ m g / d L}$ & $\mathbf{p}$ Value \\
\hline Number of patients & $90(24.2 \%)$ & $49(41.2 \%)$ & $41(16.3 \%)$ & $0.003^{*}$ \\
Peritonitis & $41(45.56 \%)$ & $21(42.86 \%)$ & $20(48.78 \%)$ & 0.727 \\
Non-compliance/operational problem & $17(18.89 \%)$ & $11(22.45 \%)$ & $6(14.63 \%)$ & 0.501 \\
Ultrafiltration insufficiency & $9(10 \%)$ & $5(10.21 \%)$ & $4(9.76 \%)$ & 1.000 \\
Dialysis inadequacy & $7(7.78 \%)$ & $2(4.08 \%)$ & $5(12.20 \%)$ & 0.3 \\
Mechanical problems/structural defect & $8(8.89 \%)$ & $5(10.20 \%)$ & $3(7.32 \%)$ & 0.914 \\
Surgical operation procedure & $5(5.56 \%)$ & $3(6.12 \%)$ & $2(4.88 \%)$ & 1.000 \\
Tunnel infection & $1(1.11 \%)$ & $0(0 \%)$ & $1(2.44 \%)$ & 0.93 \\
Other reason/unknown & $2(2.22 \%)$ & $2(4.08 \%)$ & $0(0 \%)$ & 0.555 \\
\hline${ }^{*}$ p Value $<0.05$ & & & &
\end{tabular}

failure was non-compliance or operational problems in $17(18.8 \%)$ patients.

\section{The influence of UA on all-cause technique failure}

As evidenced in table 2, technique failure occurred in 49 $(41.2 \%)$ patients in the hyperuricaemia group compared with $41(16.3 \%)$ in the normouricaemia group $(\mathrm{p}=0.003)$. The Kaplan-Meier plot demonstrated that the technique failure rate was significantly higher in the hyperuricaemia group, as compared with the normouricaemia group (figure $1, \log$-rank test, $\mathrm{p}=0.012$ ). In the multivariate Cox regression model, hyperuricaemia was significantly associated with a higher risk of technique failure (HR 1.24; 95\% CI 1.09 to $1.42, \mathrm{p}=0.001$; table 3 ), independent of other confounding factors. residual renal function (RRF), no need of assistance during dialysis exchanges and icodextrin use were negatively correlated with all-cause technique failure, whereas DM, exit-site infection and peritonitis rate were positively associated.

\section{The influence of UA on peritonitis-related technique failure}

As shown in table 2, peritonitis accounted for $42.8 \%$ of technique failure in the hyperuricemic group compared with $48.7 \%$ in the normouricaemic group ( $p=0.727$ ). The Kaplan-Meier plot clearly illustrated that peritonitisassociated technique failure rate was significantly higher in the hyperuricemic group, as compared with the normouricaemic group (figure 2, log-rank test, $\mathrm{p}=0.0323$ ) In the multivariate Cox regression model, hyperuricaemia was significantly associated with a higher risk of peritonitis-related technique failure (HR 1.29; 95\% CI 1.07 to $1.57, \mathrm{p}=0.008$; table 4 ). In addition, icodextrin use was negatively correlated with peritonitis-related technique failure, whereas peritonitis rate was positively associated.

\section{Sensitivity analysis}

The predictive role of hyperuricaemia in all-cause technique failure was further consolidated in the sensitivity

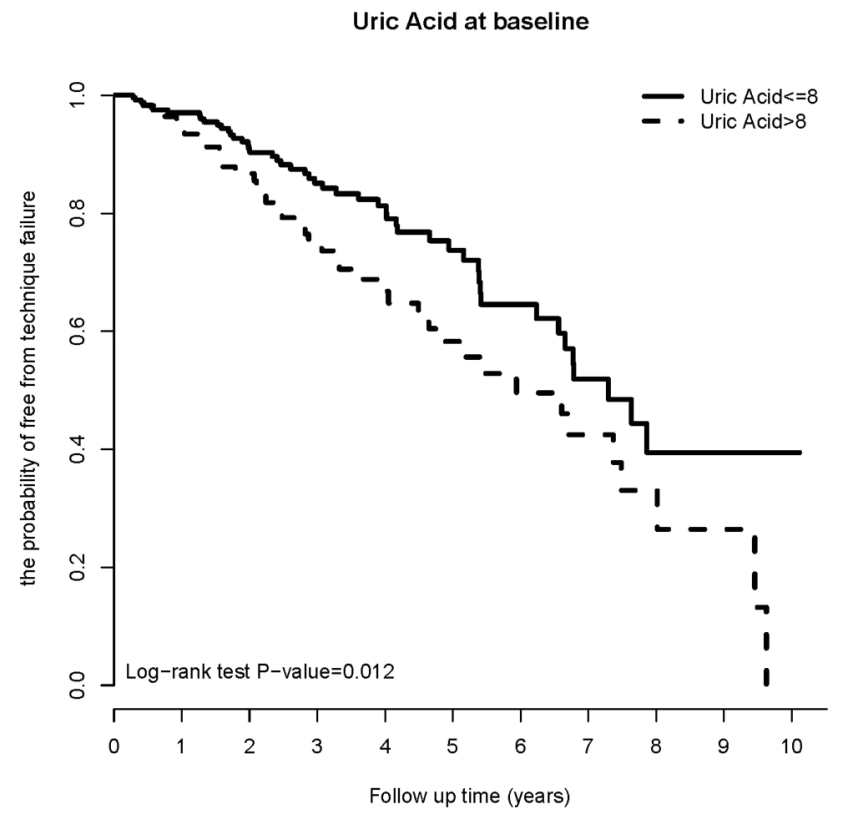

Figure 1 Kaplan-Meier plot of all-cause technique survival for baseline uric acid levels.
Table 3 Risk factors for technique failure by multivariate Cox proportional hazards regression analysis

\begin{tabular}{|c|c|c|}
\hline & HR $(95 \% \mathrm{Cl})$ & $\begin{array}{l}p \\
\text { Value }\end{array}$ \\
\hline $\begin{array}{l}\text { Residual renal function } \\
\left(\mathrm{mL} / \mathrm{min} / 1.73 \mathrm{~m}^{2}\right)\end{array}$ & 0.861 (0.76 to 0.97$)$ & $0.016^{*}$ \\
\hline Assistant (no vs yes) & $0.459(0.26$ to 0.8$)$ & $0.007^{*}$ \\
\hline Diabetes mellitus & 2.115 (1.22 to 3.66$)$ & $0.007^{*}$ \\
\hline Uric acid & 1.244 (1.09 to1.42) & $0.001^{*}$ \\
\hline Exit-site infection & 1.491 (1.1 to 2.01$)$ & $0.009^{*}$ \\
\hline Peritonitis rate & 3.118 (1.8 to 5.39$)$ & $<0.001^{*}$ \\
\hline Icodextrin use & $0.255(0.14$ to 0.45$)$ & $<0.001^{\star}$ \\
\hline \multicolumn{3}{|c|}{$\begin{array}{l}\text { The analysed variables included gender, age, BMI, comorbid } \\
\text { conditions, and the use of ACE inhibitor, ARB, } \beta \text {-blocker, CCB, } \\
\text { hypouricaemic agents, diuretics, BUN, creatinine, haemoglobin, } \\
\text { ferritin, HbA1c, serum albumin, CaxP, GPT, residual renal } \\
\text { function, icodextrin use, Balance dialysate use, assistance for } \\
\text { dialysate exchanges, peritoneal Kt/V, weekly total Kt/V urea, } \\
\text { nPNA, D/P (creatinine) at } 4 \text { hours, ultrafiltration, } 24 \text {-hour urine } \\
\text { output, and exit-site infection, tunnel infection, number of } \\
\text { exchanges per day and peritonitis rate. } \\
\text { *p Value }<0.05 \text {. } \\
\text { ARB, angiotensin II receptor blocker; BUN, blood urea nitrogen; } \\
\text { CCB, calcium channel blocker; HbA1c, glycated haemoglobin. }\end{array}$} \\
\hline
\end{tabular}


Uric Acid at baseline

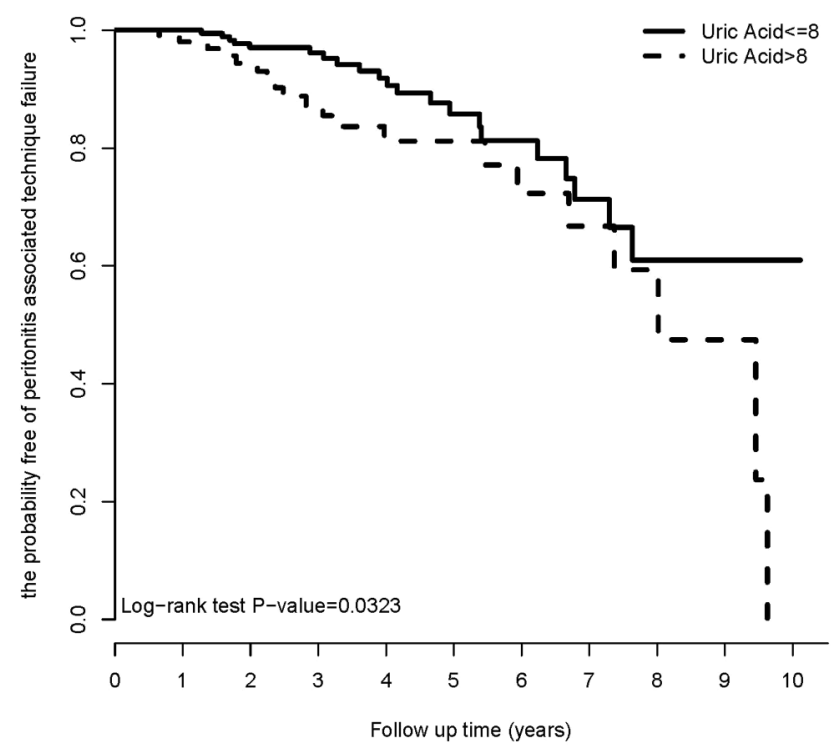

Figure 2 Kaplan-Meier plot of peritonitis-related technique survival for baseline uric acid levels.

analyses (table 5). Model S1 demonstrated that both UA tertiles 2 and 3 were associated with a higher risk of technique failure using UA tertile 1 as the reference group. Hyperuricaemia, defined by $\mathrm{UA}>7 \mathrm{mg} / \mathrm{dL}$, was also correlated with a higher risk of technique failure (model S2). The association remained significant when UA was analysed as a continuous variable (model S3). Similar to the analytic model for all-cause technique failure, UA was demonstrated to be significantly predictive of peritonitis-related technique failure in the three sensitivity analyses.

Table 4 Risk factors for technique failure due to peritonitis by multivariate Cox proportional hazards regression analysis

\begin{tabular}{lcc}
\hline & HR $(95 \%$ Cl) & p Value \\
\hline $\begin{array}{l}\text { Residual renal function } \\
\left(\mathrm{mL} / \mathrm{min} / 1.73 \mathrm{~m}^{2}\right)\end{array}$ & $0.883(0.73$ to 1.06$)$ & 0.192 \\
Body mass index & $1.088(1$ to 1.19$)$ & 0.059 \\
Uric acid & $1.298(1.07$ to 1.57$)$ & $0.008^{*}$ \\
Tunnel infection rate & $0.854(0.01$ to 54.41$)$ & 0.941 \\
Peritonitis rate & $20.960(8.33$ to 52.76$)$ & $<0.001^{*}$ \\
lcodextrin use & $0.078(0.03$ to 0.23$)$ & $<0.001^{*}$ \\
\hline
\end{tabular}

The analysed variables included gender, age, BMI, comorbid conditions, and the use of ACE inhibitor, ARB, $\beta$-blocker, CCB, hypouricaemic agents, diuretics, BUN, creatinine, haemoglobin, ferritin, $\mathrm{HbA1C}$, serum albumin, $\mathrm{CaxP}, \mathrm{GPT}$, residual renal function, icodextrin use, Balance dialysate use, assistance for dialysate exchanges, peritoneal $\mathrm{Kt} / \mathrm{V}$, weekly total $\mathrm{Kt} / \mathrm{V}$ urea, nPNA, D/P (creatinine) at 4 hours, ultrafiltration, 24-hour urine output, and exit-site infection, tunnel infection, number of exchanges per day and peritonitis rate.

${ }^{*} \mathrm{p}$ Value $<0.05$

ARB, angiotensin II receptor blocker; BUN, blood urea nitrogen; $\mathrm{CCB}$, calcium channel blocker; HbA1c, glycated haemoglobin.

\section{DISCUSSION}

In this study, we examined the relationship of serum UA level with technique failure, either all-cause or peritonitis related, in 371 patients on CAPD in a single Taiwanese PD centre and found that UA is a significant risk factor associated with both all-cause and peritonitis-related technique failure after adjusting for all the available confounding factors.

Technique failure will shorten the PD vintage and lead to transfer to HD or transplant. The reasons for patient dropout are multifactorial and can be ascribed to modality-related, patient-related or system-related factors. ${ }^{11}$ Many studies have been conducted to evaluate the risk factors of technique failure in the past two decades. A Turkish study found that technique failure was independently associated with peritonitis rate and peritoneal $\mathrm{Kt} / \mathrm{V} .^{12}$ A multicentre cohort study in India showed that non-diabetes, average transporter, nonsmoker, good nutritional status, haemoglobin $11 \mathrm{~g} / \mathrm{dL}$, low peritonitis rate and ultrafiltration of at least $1 \mathrm{~L}$ per day were associated with better survival on PD. ${ }^{13}$ A Korean multicentre study of 2163 patients on PD documented that long-term usage of icodextrin can improve technique survival. ${ }^{14}$ Using data from the Australia and New Zealand Dialysis and Transplant Registry (ANZDATA), obesity at the initiation of PD is a significant risk factor for technique failure. ${ }^{15}$

Peritonitis remains one of the most devastating complications associated with PD and continues to be the primary cause of dropout from PD, regardless of the improvement in the PD systems, such as twin-bag or Y-set systems. ${ }^{16}$ Spahioglu et $a l^{12}$ reported that peritonitis is the leading cause of technique failure and accounted for $55.8 \%$ of failures, which is similar to our current finding of $45.5 \%$. In our previous study, we demonstrated that early peritonitis and high peritonitis rate were both risk factors related to technique failure. ${ }^{17} 18$ From the current literature, many factors have been correlated with peritonitis occurrence. For example, old age, male gender, lower educational level and hypoalbuminaemia at the start of PD were the independent predictors for the first episode of peritonitis in Southern Chinese patients on CAPD. ${ }^{19}$ Regarding the determinants of technique failure following CAPD peritonitis, Yang et $a l^{20}$ showed that independent predictors included hypoalbuminaemia, longer duration of PD effluent leucocyte count above $100 / \mu \mathrm{L}$, the aetiological source of infection and the causative organism. In addition, they also found that concomitant tunnel or exitsite infection preceding peritonitis would lead to PD catheter loss.

Several mechanisms linking hyperuricaemia and technique failure were proposed. The most common cause of technique failure was refractory peritonitis in our study cohort. No significant difference was observed in terms of peritonitis rate between patients with hyperuricaemia and normouricaemia, so it is postulated that patients with hyperuricaemia might have more impaired 


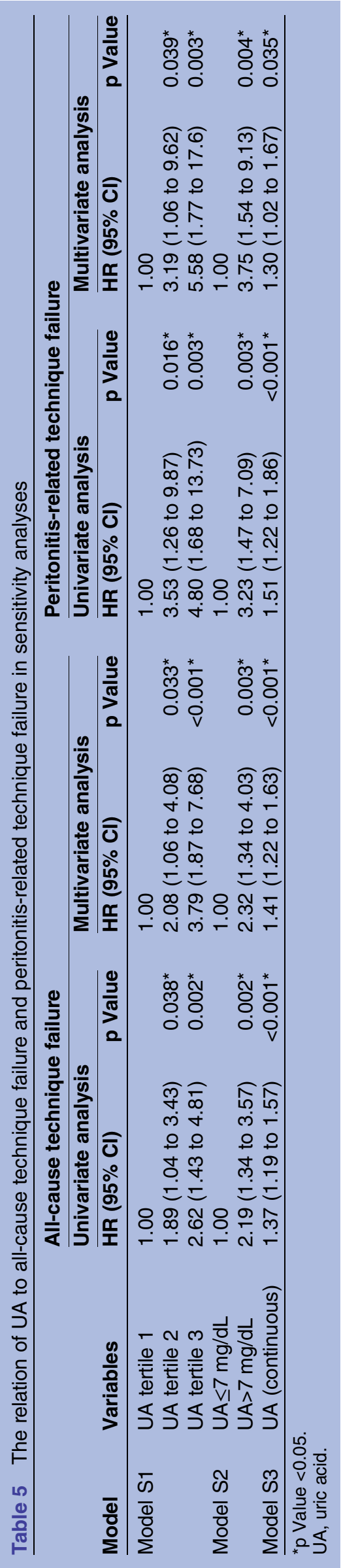

immunity than patients with normouricaemia. CKD is considered as a state of dysfunction in innate and adaptive immunity, so patients with CKD are more vulnerable to infection and respond poorly to vaccination. ${ }^{21}{ }^{22}$ Depending on the situation, UA has diverse biological characteristics of both pro-oxidant and antioxidant properties. In physiological concentration, it acts as an antioxidant that can chelate metals and scavenge free oxygen radicals. ${ }^{23}$ As a pro-oxidant, UA can oxidise lipids, reduce nitric oxide release and increase reactive oxygen species (ROS). ${ }^{24}$ The production of ROS can also consequently cause lipid peroxidation of membranes, which can impact the immune response. During infection, it is postulated that there should be an increased level of antioxidant response to equilibrate the excessive proinflammatory cytokines and oxidative stress. The more imbalances in redox state in patients with hyperuricaemia may contribute to treatment failure of peritonitis and subsequent technique failure.

Functional abnormalities of neutrophils, monocytes and dendritic cells are directly associated with increased susceptibility of infection in patients on CKD. ${ }^{25-27}$ Neutrophils play a crucial role in the innate immunity as the first line of defence against infections. Neutrophil extracellular traps (NETs), primarily composed of DNA from neutrophils and extracellular fibres, have emerged as a novel mechanism responsible for killing invading pathogens recently. ${ }^{28}$ Generally, ROS production by NADPH oxidase (Nox) is required for NETs formation. However, Arai $e t a l^{9}$ demonstrated that UA alone can induce NETs formation in a Nox-independent pathway. NETs resemble a double-edged sword; they can fight infections or cause morbidities. Excessive NETs formation is shown to cause inflammatory and autoimmune diseases. One may speculate that hyperuricaemia can directly, or indirectly by ROS formation, cause disproportionate NETs that lead to unfavourable prognosis in infections. In addition, hyperuricaemia was also known to stimulate the proinflammatory mechanisms by promoting the generation of interleukin-1 $\beta$, IL- 6 and tumour necrosis factor. ${ }^{5}$ Increased serum levels of IL-6 have been correlated with increased production of Wnt signalling proteins. ${ }^{30}$ From experimental studies, Wnt5a is expressed during differentiation of human monocytes to macrophages or dendritic cells and its expression causes more tolerance and less response of dendritic cells to infection. ${ }^{31}$ Besides, the Wnt/ $\beta$-catenin pathway inhibits transendothelial migration of monocytes and enhances their adhesion to the endothelium. ${ }^{32} 33$ Macrophages are the predominant cells that provide the immune response against infection in the peritoneum. ${ }^{34}$ Thus, one can postulate that an upregulated Wnt pathway by the stimulation of IL- 6 may have a negative impact on the immunity of patients with hyperuricaemia, which is more severe than that on patients with normouricaemia.

Other additional explanations for the association of hyperuricaemia and all-cause technique failure can also 
be considered, although these may not be related to peritonitis-related technique failure. First, hyperuricaemia was shown to accelerate RRF decline in patients on PD. ${ }^{35}$ Given that loss of RRF was strongly related to PD peritonitis, a greater risk of technique failure is anticipated in patients on hyperuricaemia. However, we did not evaluate the slope of RRF in this study. Second, high UA levels can induce hypertension through activation of the renin-angiotensin-aldosterone (RAA) system. ${ }^{36}$ Some evidence indicates that RAA system activation may lead to tissue fibrosis, and that the expression of MCP-1 and TGF- $\beta 1$ by angiotensin II stimulation can promote deposition of the extracellular matrix. ${ }^{37} 38$ Thus, hyperuricaemia may eventually contribute to peritoneal fibrosis and technique failure. Third, high oxidative stress was previously observed in participants with high serum UA levels. $^{5}$ Since peritoneal hyperpermeability, mesothelial loss and fibrosis can be induced by acute oxidative stress in experimental models, ${ }^{39}$ we speculated that hyperuricaemia may potentiate functional and structural change of peritoneum and ultrafiltration failure.

Since our study consisted of incident patients on CAPD, we were able to avoid the potentially confounding factors associated with chronically treated CAPD. The strengths of this study must also be balanced against its weakness. This single-centre investigation with retrospective observation precludes us from clarifying the underlying mechanisms linking hyperuricaemia and death-censored technique failure. Moreover, our data did not provide information on whether patient's hand hygiene condition, wearing a face mask or the environmental conditions during exchanging dialysates, all of which would be prone to technique failure. Our study is also limited by the lack of UA clearance by PD, which may help understand the PD treatment per second on the technique survival. In addition, the association of UA with the composite outcome (mortality and technique failure) awaits further investigation.

The retrospective nature of this study prevents us from addressing whether patients with hyperuricaemia would benefit from receiving HD from the beginning and whether lower serum UA level, either by diet or pharmacological treatment, would prolong the technique survival. Patients on CAPD with hyperuricaemia should be closely monitored and strategies of increasing survival on CPAD should be taken. Manipulations to prevent and handle peritonitis, dialysis inadequacy, ultrafiltration failure, as well as education of patients and healthcare staff, may help to prolong the usage of CAPD.

\section{Author affiliations}

${ }^{1}$ Ph.D. program in Translational Medicine, College of Life Science, National Chung Hsing University, Taichung, Taiwan

${ }^{2}$ Division of Nephrology, Department of Internal Medicine, Changhua Christian Hospital, Changhua, Taiwan

${ }^{3}$ School of Medicine, Kaohsiung Medical University, Kaohsiung, Taiwan

${ }^{4}$ School of Medicine, Chung Shan Medical University, Taichung, Taiwan

${ }^{5}$ Institute of Biomedical Sciences, College of Life Science, National Chung Hsing University, Taichung, Taiwan
Acknowledgements The authors thank all the PD nursing teams for their help in collecting data.

Contributors $\mathrm{YY}$ and $\mathrm{C}-\mathrm{CC}$ conceived and designed the experiments. Y-KW and $\mathrm{C}-\mathrm{CL}$ performed the experiments. P-FC and C-TK analysed the data. Y-PH wrote the paper.

Funding This research received no specific grant from any funding agency in the public, commercial or not-for-profit sectors.

Competing interests None declared.

Ethics approval The study protocol was in accordance with the Declaration of Helsinki and approved by the Institutional Review Board of Changhua Christian Hospital (CCH IRB grant number 150505).

Data sharing statement All the data relevant to the study are included in the submitted manuscript. No additional data are available.

Open Access This is an Open Access article distributed in accordance with the Creative Commons Attribution Non Commercial (CC BY-NC 4.0) license, which permits others to distribute, remix, adapt, build upon this work noncommercially, and license their derivative works on different terms, provided the original work is properly cited and the use is non-commercial. See: http:// creativecommons.org/licenses/by-nc/4.0/

\section{REFERENCES}

1. Harrison R. Structure and function of xanthine oxidoreductase: where are we now? Free Radic Biol Med 2002;33:774-97.

2. Doehner W, Schoene N, Rauchhaus M, et al. Effects of xanthine oxidase inhibition with allopurinol on endothelial function and peripheral blood flow in hyperuricemic patients with chronic heart failure: results from 2 placebo-controlled studies. Circulation 2002;105:2619-24.

3. Puig JG, Ruilope LM. Uric acid as a cardiovascular risk factor in arterial hypertension. J Hypertens 1999;17:869-72.

4. Lee J, Sparrow D, Vokonas PS, et al. Uric acid and coronary heart disease risk: evidence for a role of uric acid in the obesity-insulin resistance syndrome. The Normative Aging Study. Am J Epidemiol 1995;142:288-94.

5. Johnson RJ, Kang DH, Feig D, et al. Is there a pathogenetic role for uric acid in hypertension and cardiovascular and renal disease? Hypertension 2003;41:1183-90.

6. Wannamethee SG. Serum uric acid and risk of coronary heart disease. Curr Pharm Des 2005;11:4125-32.

7. Suliman ME, Johnson RJ, García-López E, et al. J-shaped mortality relationship for uric acid in CKD. Am J Kidney Dis 2006;48:761-71.

8. Feng $\mathrm{S}$, Jiang L, Shi $\mathrm{Y}$, et al. Uric acid levels and all-cause mortality in peritoneal dialysis patients. Kidney Blood Press Res 2013;37:181-9.

9. Oreopoulos DG, Robson M, Faller B, et al. Continuous ambulatory peritoneal dialysis: a new era in the treatment of chronic renal failure. Clin Nephrol 1979;11:125-8.

10. Kolesnyk I, Dekker FW, Boeschoten EW, et al. Time-dependent reasons for peritoneal dialysis technique failure and mortality. Perit Dial Int 2010;30:170-7.

11. Chaudhary K. Peritoneal dialysis drop-out: causes and prevention strategies. Int J Nephrol 2011;2011:434608.

12. Sipahioglu MH, Aybal A, Unal A, et al. Patient and technique survival and factors affecting mortality on peritoneal dialysis in Turkey: 12 years' experience in a single center. Perit Dial Int 2008;28:238-45.

13. Abraham G, Kumar V, Nayak KS, et al. Predictors of long-term survival on peritoneal dialysis in South India: a multicenter study. Perit Dial Int 2010;30:29-34.

14. Han SH, Ahn SV, Yun JY, et al. Effects of icodextrin on patient survival and technique success in patients undergoing peritoneal dialysis. Nephrol Dial Transplant 2012;27:2044-50.

15. McDonald SP, Collins JF, Johnson DW. Obesity is associated with worse peritoneal dialysis outcomes in the Australia and New Zealand patient populations. J Am Soc Nephrol 2003;14:2894-901.

16. Woodrow G, Turney JH, Brownjohn AM. Technique failure in peritoneal dialysis and its impact on patient survival. Perit Dial Int 1997;17:360-4.

17. Hsieh YP, Wang SC, Chang CC, et al. The negative impact of early peritonitis on continuous ambulatory peritoneal dialysis patients. Perit Dial Int 2014;34:627-35. 
18. Hsieh YP, Chang CC, Wang SC, et al. Predictors for and impact of high peritonitis rate in Taiwanese continuous ambulatory peritoneal dialysis patients. Int Urol Nephrol 2015;47:183-9.

19. Fan X, Huang R, Wang J, et al. Risk factors for the first episode of peritonitis in Southern Chinese continuous ambulatory peritoneal dialysis patients. PLOS ONE 2014;9:e107485.

20. Yang CY, Chen TW, Lin YP, et al. Determinants of catheter loss following continuous ambulatory peritoneal dialysis peritonitis. Perit Dial Int 2008;28:361-70.

21. Hauser $A B$, Stinghen $A E$, Kato $S$, et al. Characteristics and causes of immune dysfunction related to uremia and dialysis. Perit Dial Int 2008;28(Suppl 3):S183-7.

22. Kato $\mathrm{S}$, Chmielewski $\mathrm{M}$, Honda $\mathrm{H}$, et al. Aspects of immune dysfunction in end-stage renal disease. Clin J Am Soc Nephrol 2008;3:1526-33.

23. Ames BN, Cathcart R, Schwiers E, et al. Uric acid provides an antioxidant defense in humans against oxidant- and radical-caused aging and cancer: a hypothesis. Proc Natl Acad Sci USA 1981;78:6858-62.

24. Leyva F, Anker S, Swan JW, et al. Serum uric acid as an index of impaired oxidative metabolism in chronic heart failure. Eur Heart $J$ 1997; 18:858-65.

25. Lim WH, Kireta S, Leedham E, et al. Uremia impairs monocyte and monocyte-derived dendritic cell function in hemodialysis patients. Kidney Int 2007;72:1138-48.

26. Verkade MA, van Druningen CJ, Vaessen LM, et al. Functional impairment of monocyte-derived dendritic cells in patients with severe chronic kidney disease. Nephrol Dial Transplant 2007;22:128-38.

27. Anding K, Gross P, Rost JM, et al. The influence of uraemia and haemodialysis on neutrophil phagocytosis and antimicrobial killing. Nephrol Dial Transplant 2003:18:2067-73.

28. Brinkmann V, Zychlinsky A. Beneficial suicide: why neutrophils die to make NETs. Nat Rev Microbiol 2007;5:577-82.

29. Arai $Y$, Nishinaka $Y$, Arai T, et al. Uric acid induces NADPH oxidase-independent neutrophil extracellular trap formation. Biochem Biophys Res Commun 2014;443:556-61.
30. Katoh M, Katoh M. Transcriptional mechanisms of WNT5A based on NF-kappaB, Hedgehog, TGFbeta, and Notch signaling cascades. Int J Mol Med 2009;23:763-9.

31. Valencia J, Hernández-López C, Martínez VG, et al. Wnt5a skews dendritic cell differentiation to an unconventional phenotype with tolerogenic features. $J$ Immunol 2011:187:4129-39.

32. Tickenbrock L, Schwäble J, Strey A, et al. Wnt signaling regulates transendothelial migration of monocytes. J Leukoc Biol 2006;79:1306-13.

33. Lee DK, Nathan Grantham R, Trachte AL, et al. Activation of the canonical Wnt/beta-catenin pathway enhances monocyte adhesion to endothelial cells. Biochem Biophys Res Commun 2006;347:109-16.

34. Lewis $\mathrm{S}$, Holmes $\mathrm{C}$. Host defense mechanisms in the peritoneal cavity of continuous ambulatory peritoneal dialysis patients. 1. Perit Dial Int 1991;11:14-21.

35. Park JT, Kim DK, Chang TI, et al. Uric acid is associated with the rate of residual renal function decline in peritoneal dialysis patients. Nephrol Dial Transplant 2009;24: 3520-5.

36. Mazzali M, Hughes J, Kim YG, et al. Elevated uric acid increases blood pressure in the rat by a novel crystal-independent mechanism. Hypertension 2001;38:1101-6.

37. Gibbons GH, Pratt RE, Dzau VJ. Vascular smooth muscle cell hypertrophy vs. hyperplasia. Autocrine transforming growth factor-beta 1 expression determines growth response to angiotensin II. J Clin Invest 1992;90:456-61.

38. Lemarie' CA, Simeone SM, Nikonova A, et al. Aldosterone-induced activation of signaling pathways requires activity of angiotensin type 1a receptors. Circ Res 2009;105:852-9.

39. Gotloib L, Wajsbrot V, Cuperman $\mathrm{Y}$, et al. Acute oxidative stress induces peritoneal hyperpermeability, mesothelial loss, and fibrosis. J Lab Clin Med 2004;143:31-40. 